\title{
LAS REACCIONES DE LA POBLACIÓN ALICANTINA FRENTE A LA EPIDEMIA DE FIEBRE AMARILLA DE 1804*
}

\author{
Mercedes PASCUAL ARTIAGA
}

Universidad de Alicante

\begin{abstract}
Resumen
El trabajo analiza a través de la revisión de diversas fuentes manuscritas, las reacciones suscitadas en el seno de la población alicantina a raíz de la epidemia de fiebre amarilla de 1804. Los resultados ponen de manifiesto la diversidad socioeconónica de los comportamientos. Mientras los hacendados y comerciantes emigraron en su mayor parte, otros colectivos, como los militares o parte del clero, permanecieron en la ciudad al frente de muchas de las iniciativas político-admnistrativas o filantrópicas que se tomaron. Las clases populares fueron las que más padecieron los efectos de la epidemia, lo que provocó el resentimiento y la rebeldía a la hora de aceptar y de cumplir las órdenes impuestas por las autoridades. La aparición de la fiebre amarilla, con la consiguiente paralización de la vida comercial y laboral, agravó los problemas que acompañaban a la población alicantina en 1804: crisis agraria, conflicto bélico, desabastecimiento, condiciones higiénico-sanitarias deficientes, etc.
\end{abstract}

\begin{abstract}
This study analizes, through a revision of numerous varied handwritten documents. the reaction of the Alicantine population stemming from the yellow fever epidemic of 1804. The results of this investigation reveal a great diversity of behaviours throughout the socio-economic strata. While the majority of Alicante's landowners and merchants emigrated, other groups, such as members of the military and part of the clergy, remained in the city, at the head of many of the political and administrative initiatives that were adopted. The lower classes suffered most the effects of the epidemic. provoking resentment and rebellion when it came time to accept and act on the orders of the authorities. The arrival of the yellow fever and the subsequent paralization of commerce and work in the city aggravated the problems already faced by the people of Alicante in 1804: a national agrarian crisis, war with England, a scarcity of provisions, deplorable health and hygienic conditions, etc.
\end{abstract}

* Este trabajo es una parte de la Memoria de Investigación titulada Hambre, enfermedad y muerte. La sociedad alicantina frente a la epidemia de fiebre amarilla de 1804, dirigida por el doctor Josep Bermabeu 
«És molt més fàcil posar al día un punt de vista intel-lectual que canviar, en la mateixa intensitat, el comportament davant dels altres $i$ del món»

Joan Reglà (Comprendre el món, 1967, p.106)

\section{INTRODUCCIÓN}

El estudio de las enfermedades de comportamiento epidémico incluye a menudo las reacciones de la población ' como respuesta a una situación de grave desequilibrio donde la enfermedad además de un problema de salud se convierte en un problema social. Este tipo de patologías hacían cundir el pánico entre las gentes pues no se conocían remedios eficaces $\mathrm{y}$, víctimas de ellas, gran cantidad de personas morían en un corto período de tiempo sin saber como protegerse adecuadamente para escapar a un trágico destino. Este desconocimiento de la enfermedad convertía a la medicina en una ciencia empírica sin recursos curativos y sólo con algunos recursos preventivos que en ocasiones provocaban un deterioro mayor de las condiciones de vida de los

Mestre del departamento de Salud Pública de la Universidad de Alicante en el marco del programá de doctorado de Historia de la Ciencia y la Documentación Científica. Fue presentada en marzo de 1998 , permaneciendo inédita en la actualidad.

1. Con un esquema de análisis similar al desarrollado en este trabajo, podemos citar, entre otras, las publicaciones siguientes: PORRAS GALLO, Ma Isabel (1997), Un reto para la sociedad madrileña: la epidemia de gripe de 19/8-19. Consejeria de Educación y Cultura de la Comunidad de Madrid, ed. Complutense. Madrid; BERNABEU MESTRE, Josep (Coord.) (1991), La ciutat davant el coniagi. Alacant $i$ la grip de 1918-19. Conselleria de Sanitat i Consum (Monografies sanitàries, sèrie B. clàssics); 4. València; CARRILLO, Juan Luis; GARCIA BALLESTER, Luis (1981), Enfermedad y sociedad en la Málaga de los siglos XVIII y XIX. I. La fiebre amarilla (1741-182I). Secretariado de publicaciones de la Universidad de Málaga y Excma. Diputación Provincial. Málaga. pp. 49-108; PÉREZ MOREDA, Vicente (1980), Las crisis de mortalidad en la España interior. Siglos XVI-XIX. Siglo XXI de España editores. Madrid. pp. 224-231: RUBIO VELA, Agustín (1979), Peste negra, crisis y compontamientos sociales en la España del siglo XIV. La ciudad de Valencia (1348-1401). Secretariado de publicaciones de la Universidad de Granada. Granada, pp. 55-84; PLA ALBEROLA, Primitivo (1985). «Hambre. peste y guerra: Cocentaina (1609-1709)». Rev. Hist. Mod; 5: 67-126, especialmente: 68-76; BERNABEU MESTRE, J; PERDIGUERO GIL, E. (1994), «Epidemia y pluralidad asistencial: a propósito del 'andancio' de fiebre amarilla de 1888 en Santa Cruz de la Palma (Islas Canarias)», en: CARRILLO, J.L; OLAGÜE DE ROS, G., ed: Acias del XXXIII Congreso Internacional de Historia de la Medicina, pp. 89-100. Sevilla; BERNABEU MESTRE, J; RAMOS SEGURA, J.R. (1995), «Malaltia, poder i control social: El desallotjament de la barriada alacantina de les províncies amb motiu de la grip de 1918», en: Actes de les III Trobades d'Història de la Ciència i de la Tècnica als Països Catalans. SCHCT. Barcelona, pp. 215-221; RODRIGUEZ OCAÑA, E. (1987), La constitución de la medicina social como disciplinat en España (1882-1923). Ministerio de Sanidad y Consumo. Madrid. Sobre las desigualdades sociales ante la enfermedad y la muerte son interesantes las opiniones de: EVANS, R.J. (1987), Death in Hambourg. Society and politics in the cholera years 1830-1910. Oxford University Press. Oxford. pp. 158-159; REHER, D., «Les ciutats i les crisis a l'Espanya Moderna». Estudis d'Història Agrìria; 5: $91-114 ;$ LEBRUN, F (1988), Preface, en: BARDET, J.P. (ed.). Peurs et terreurs face a la contagion. Fayard. Paris. pp. 7-14; FERNÁNDEZ SANZ, J.J. (1990), 1885: El año de la vacunación de Ferrán. Transfondo politico, médico, sociodemográfico y económico de una epidemia. Fundación Ramón Areces. Otro aspecto que con frecuencia se estudia, en relación a las reacciones de la población, es el incremento de la religiosidad ante la aparición de brotes epidémicos, en este sentido cabe citar a: BOURDELAIS, P. (1988), «Le choléra. Presentation» en: BARDET, J.P. (ed.) op.cit; EGGERICK, TH; POULAIN, M. (1988), «L'epidémie de choléra en 1886. Le cas de la Belgique», en: BARDET, J.P. (ed.), op.cit. 
menos favorecidos socialmente. El mismo desconocimiento a que aludíamos más arriba aportaba a estas patologías cierto carácter demoníaco y fatalista. En esta situación extrema y terrible, viendo perecer a familiares y vecinos en un corto plazo, no es extraño que cada cual procurase su propia seguridad olvidando, en general, los más elementales sentimientos humanos.

La aparición de entidades nosológicas como la fiebre amarilla, supusieron para Alicante una conmoción, no sólo por la enfermedad en sí, sino por todos los factores que la acompañaban. ${ }^{2}$ Se trataba de una enfermedad epidémica poco conocida, sin tradición en cuanto a remedios profesionales y ante la cual la sabiduría popular carecía de recursos. De naturaleza «exótica», de difícil diagnóstico y pronóstico y sin tratamientos eficaces. Enfermedad que cursaba en su período más grave con unos síntomas terribles y agravado todo ello por las medidas de aislamiento, seguidas por los contagionistas y adoptadas por el poder, que recluían en la ciudad mediante cordones sanitarios a sus habitantes fuertemente custodiados por tropas militares y por personal civil. Esta situación era padecida por todos aquéllos que no podían emigrar de la ciudad y especialmente sufrida por los sectores sociales más pobres que quedaban privados, con la suspensión de la actividad normal y la incomunicación, del jornal diario que les permitía subsistir. La inactividad, la miseria, el pánico ante el contagio de personas próximas, la imposibilidad de huir, la falta de efectividad de los remedios médicos y el propio miedo a enfermar y a morir serían algunas de las circunstancias que acompañarían la tragedia que supuso en Alicante la irrupción de la fiebre amariIla en 1804.

No todos los sectores de la población vivieron y sufrieron la epidemia de fiebre amarilla de la misma manera, por lo que parece conveniente tomar en consideración distintos colectivos. En principio, y con matices, se pueden establecer cuatro grupos. Un primer grupo de comerciantes y hacendados, un segundo grupo constituido por los militares, un tercero que incluiría a los eclesiásticos y el cuarto formado por el grueso de las clases populares y los pobres de solemnidad. El primer grupo, de comerciantes y hacendados, emigró en su mayor parte al sospecharse la epidemia y sólo sufrió las consecuencias económicas de la misma. El segundo grupo, los militares,

2. En relación a las fuentes documentales manuscritas consultadas para la realización de este trabajo, se han revisado en el Archivo Municipal de Alicante los Libros de actas del ayuntamiento de Alicante de los años 1803. 1804 y 1805; las series de Sanidad, Legajo 1; serie de Beneficencia, Legajo 1; serie de Correspondencia, Legajos 2, 3 y 4; el Libro de Interrogatorios del año 1803; los Libros de Expedientes y Veredas 34, 35, 36 y 37, correspondientes a los años 1803 a 1806; la serie de Fiestas, años 1800-1824 y el libro de Reales Provisiones de los años 1802-1804. También se han consultado manuscritos del Archivo de la Real Academia Nacional de Medicina de Madrid y en el Archivo Histórico de Orihuela los legajos de epidemias de 1804 y 1805. En el Archivo Histórico Provincial de Alicante se han revisado protocolos notariales relativos a la ciudad de Alicante, San Juan y Benimagrell de los años 1803, I804 y 1805. Han sido igualmente de gran interés una serie de artículos publicados en el Diario de Alicante, año XVII: noviembre y diciembre de 1927, que bajo el título «La peste de 1804» y atribuidos a E. IR LES GARRIGÓS, ofrecieron numerosa información para la elaboración del trabajo. Además de otra serie de fuentes impresas que se señalaran oportunamente en las notas que ofrezcamos.

3. Sobre la población de la ciudad de Alicante que en 1804 fue afectada por la epidemia, cabe destacar que. de una población estimada en alrededor de 13.957 habitantes, enfermaron 9.473. murieron 2.472 y emigraron 2.110. Esto supuso la pérdida de aproximadamente el $18 \%$ de los efectivos poblacionales. 
permaneció en la ciudad al frente de muchas de las iniciativas político-administrativas que se tomaron, sufriendo las carencias y temores provocados por la epidemia. Los eclesiásticos reaccionaron de forma diversa, unos emigraron y otros permanecieron en la ciudad, bien aportando consuelo espiritual, bien atendiendo el Lazareto y en otras ocasiones aportando limosnas para el socorro de la población. Las clases populares fueron las que más padecieron en la epidemia pues, al paralizarse prácticamente la vida comercial y laboral y carecer de recursos para emigrar, quedaron a merced de la caridad incrementando el grupo más desfavorecido que constituían los pobres.

La situación de pobreza antes de declararse la epidemia era contemplada por las autoridades con gran preocupación. Gran parte de las medidas adoptadas para paliar el desempleo, el hambre y la miseria, eran legisladas para evitar actos de violencia por parte de la población que carecía de medios con que subsistir. ${ }^{4}$ La epidemia de fiebre amarilla de 1804 agravó otros problemas ya existentes anteriormente en Alicante, entre los cuales se encontraban la crisis agrícola, ${ }^{5}$ la situación bélica, el desabastecimiento de la población y el trato preferente que se dispensaba a la corte en Madrid en cuanto al aprovisionamiento de alimentos. Estos problemas acentuaron el resentimiento y la rebeldía de la población a la hora de aceptar las órdenes impuestas. Otro de los problemas que se detectan es el alto grado de analfabetismo y la diferente lengua que se empleaba por la mayoría de la población alicantina -el valenciano- y los militares y tropas que servían en Alicante -la mayoría de los cuales hablaba el castellano- lo que provocaba a menudo problemas de falta de entendimiento.

4. Algunos documentos muestran claramente la situación: AMA. Expedientes y Veredas. Arm. 15, Lib. 34. Año 1803. Carta firmada por don Manuel Antonio de Santisteban en fecha 7 de octubre de 1803, dirigida al corregidor de la ciudad de Alicante. Las medidas que se proponían era la realización de obras para proporcionar empleo a los necesitados mientras durase la situación de escasez. No obstante anima al corregidor a que los eclesiásticos colaboren con las limosnas en estas obras, en lugar de repartirlas a las puertas de las iglesias sin distinción. Así mismo debía llamarse a la generosidad a los pudientes de la ciudad: «Ha reflexionado el Consejo sobre las malas conseqüencias que traeria al bien público y particular la falta de ocupación de los muchos trabajadores y jornaleros que la esterilidad del presente año ha de dexar abandonados a la miseria sin poder adquirir el sustento para si y sus familias por otro medio que el de la limosna; siendo de temer que no alcanzando esta para socorrer a todos, se precipiten muchos a cometer excesos y delitos perjudiciales a la quietud y sosiego de las provincias, y conservación de los intereses particulares. Estas consideraciones y otras que, estimulado de su zelo por el bien público, ha expuesto el señor fiscal [...] han convencido al Consejo de la necesidad de fomar providencias eficaces y actives para el mantenimiento del pobre jornalero en la temporada rigorosa del invierno, y prevenir el crimen, la hambre, las enfermedades y demás resultas pernicioscis que de ello se originan...»; Sobre la existencia de cuadrillas de malhechores y la falta de seguridad en los caminos, una real instrucción del 29 de junio de 1784 ordenaba la persecución, aprensión y exterminio de los malhechores o ladrones: AMA. Expedientes y Veredas. Arm. 15, Lib. 34. Año 1803. Fol. 246. Carta al corregidor de Alicante, de fecha 17 de mayo de 1803.

5. Numerosos documentos del AMA reflejan la grave crisis agrícola que afligió el pás a principios del siglo XIX y que produjo una carencia generalizada de granos, en especial de trigo. Sobre la crisis de subsistencias puede revisarse: GIMÉNEZ LÓPEZ, E. (1981), Alicante en el siglo XVIII. Economía de una ciudad portuaria en el antiguo régimen, Valencia, Institució Alfons el Magnìnim, Diputació de València, pp. 265-307; PÉREZ MOREDA, V. (1984), «Consum deficitari, fam i crisis demogràfiques a l'Espanya dels segles XVI-XIX», Estudis d'Història Agrària; 5: 7-24; PÉREZ MOREDA, V. (1980), op. cit. pp. $375-377$ y $407-408$.

6. El problema de la comunicación debido a la lengua se puso de manifiesto en el cordón sanitario, hasta el punto que el comandante general del cordón, don Pedro de Buck y O'Donell, escribió al gobernador 
La mayoría de la población alicantina no confiaba en las medidas que las autoridades debían adoptar para su protección, ni tampoco en su pronta instauración. De hecho, cuando los primeros casos de fiebre amarilla en tripulantes de los buques guardacostas se conocieron en la ciudad, surgieron comentarios entre los vecinos ante la negativa de las autoridades sobre la existencia de alguna enfermedad epidémica y la ocultación de los hechos. ${ }^{7}$ Ante esta desconfianza, el gobernador divulgó un bando procurando tranquilizar a la población asegurando que las enfermedades que se habían padecido en los buques guardacostas pertenecían a «la especie de calenturas pútridas». ${ }^{8}$ A finales de agosto el gobernador de Alicante, apoyado por la opinión de los médicos, continuó asegurando que la ciudad se encontraba en perfecto estado de salud. "El 11 de septiembre el gobernador mandó reunirse a los médicos de Alicante, que emitieron un dictamen confirmando lo anterior. ${ }^{10}$ Sin embargo, el día 13 del mismo mes, el gobernador, al que le habían llegado el día anterior rumores acerca de contrabando recibido en una de las calles de la ciudad por donde habían comenzado a aparecer las enfermedades sospechosas, ${ }^{11}$ mandó a los médicos reunirse de nuevo. Éstos reconsideraron su dictamen anterior y concluyeron declarando que se trataba de las denominadas comúnmente «amarillas», que pertenecían al Thiphus Hicterodes de Sauvages, y que los franceses llamaban enfermedad del Siam, otros fiebre marinera y los españoles vómito prieto o negro, por ser éste uno de los síntomas más peligrosos, «según tenemos observado cada uno de nosotros en bastantes enfermos, que están a nuestro cuidado». ${ }^{2}$ El día 13 de septiembre, se reconoce que en Alicante existe fie-

Betegón comunicándole que, para evitar los abusos que se cometían en el cordón, enviaba un sujeto de confianza «sabedor de la lengua del país». Diario de Alicante, 14/XI/1927.

7. AMA. Sanidad. Legajo 1, $n^{\circ}$ 21, h. 3. Memorial de don Antonio Gosalves y Riera, noble de la ciudad. Almoradí, 14 de diciembre de 1804: «...los filertes rumores de todo el pueblo para que hicieran hir al Lazareto de Mahón a los guardacostas porque estavan apestados haviendo en el baluarte gente del pueblo alarnada para no permitirles a saltar, aunque antes ya lo havian practicado y llevado enfermos al Hospital, los que murieron de epidemia, y se consideraron las quadras donde havian estado por peligrosas, llevando los restantes al Hospital de los Ángeles; y siendo mucho el número de enfermos en la ciadad, se prohibió el toque de campana, para que la gente no se amedrentase más de lo que estava, y conociese el número de muertos, y en estas críticas dirigiendo oficios a las justicias circumbecinas manifestando que la ciudad estava libre y sana de contagio...»

8. Diario de Alicante, $9 / \mathrm{XI} / 1927$.

9. AMA. Sanidad. Legajo $1, n^{\circ} 6$ bis. Con fecha 27 de septiembre de 1804 , se refieren una serie de documentos para facilitar al encargado de la epidemia, don Ambrosio Lorite, la emisión del juicio sobre el origen de las enfermedades contagiosas que se padecían en Alicante. Entre ellos es citado un documento en el que los médícos de la ciudad declaraban que el pueblo de Alicante nunca había gozado de mejor salud, pero entre los documentos conservados en el AMA no lo hemos encontrado.

10 AMA. Sanidad. Legajo 1, n 6 bis. Dictamen de los médicos. 11/IX/1804.

11. AMA. Sanidad. Legajo $1, n^{\circ} 6$ bis. Carta del médico Thomás al gobernador don José Betegón, de fecha, 12/IX/1804.

12. AMA. Sanidad. Legajo $1, n^{\circ} 6$ bis. Dictamen de los médicos 13/IX/1804, donde se modifica la opinión respecto al dictamen emitido el día 11 de septiembre, y en atención a los rápidos progresos hechos por la enfermedad en pocos días, los fenómenos que presentaba, el modo en que se había propagado y el hecho de que todas ellas participaban de «un mismo genio a pesar de las variedades individuales de los sujetos que atacaban»» se reconoce a la enfermedad como fiebre amarilla. La dificultad en el diagnóstico, según los médicos, se debió a que no tenían «novedad los vecinos más infelices, por los que suelen 
bre amarilla y se declara oficialmente la epidemia. ${ }^{13}$ En el último dictamen los médicos propusieron las primeras medidas para evitar la extensión de la enfermedad, consistentes en aislar la calle Mayor y adyacentes por donde comenzó la misma. Los enfermos debían separarse de los individuos sanos mediante su aislamiento y así mismo debía facilitarse alimentos a los indigentes. Estas medidas fueron ordenadas rápidamente por las autoridades de las Juntas de Sanidad Suprema, Provincial y Municipal. La ciudad fue aislada mediante un cordón sanitario custodiado por tropas militares así como por personas civiles que garantizase la reclusión de toda la población y de las mercancías a fin de no extender la enfermedad a otras poblaciones. ${ }^{14}$ Para el aislamiento de los enfermos se organizaron lazaretos. El más activo de todos ellos fue el establecido en el convento de San Francisco. ${ }^{15}$ Otros lazaretos llamados de curación y de observación fueron establecidos en diversos lugares para acoger a las personas convalecientes o a las que debían cumplir cuarentena. ${ }^{16}$ Poco después de declararse la

empezar las epidemias», por lo que declaraban debía hacerse un esfuerzo para evitar «que se infesten estas gentes, cuyos reducidos posibles, falta de ropa blanca y aseo debido, poca o ninguna ventilación y amontonadas unas sobre otras hacen multiplicar enormemente el contagio», circunstancia que podría ayudar a asolar de esta forma a toda la provincia.

13. AHO. FM. D. 1239, n 13. Carta del Sr. Betegón a los Sres. del ayuntamiento de Orihuela, fechada en Alicante a 16 de septiembre de 1804, en la cual se informa de la declaración de la epidemia por parte de los médicos el día 13 y responsabiliza de la epidemia al contrabando y al citado Francisco, «que ha muerto, su muger con parte de su familia y todos los que tubieron parte en el contrabando».

14. Diario de Alicante, 14/XV/1927. El cordón sanitario se formó con los soldados del regimiento de América, que obedecían las órdenes del Mariscal don Pedro de Buck y O'Donell, nombrado comandante general del cordón sanitario, y que residió en Elche durante la epidemia. También colaboraban personas civiles. El cordón de soldados siguiendo la costa y a través del campo alicantino cercó la ciudad Las normas que debían garantizar la eficacia del cordón fueron impuestas desde la Junta Suprema de Sanidad. El conde de Montarco dictó las mismas órdenes que se siguieron desde 1800 en las epidemias de Cádiz, Málaga y Cartagena; AMA. Sanidad. Legajo 1, n 7 bis. Carta fechada en Elche a 17 de octubre de 1804. Noticias sobre la línea del cordón de Tibi. El cordón se componía con estacas, cuerdas y cordón; se establecían «puntos de barraca», por donde debían pasar obligatoriamente las personas que pretendían entrar o salir. Cuando una ciudad se acordonaba, los individuos que accedían al cordón o querían desplazarse, debían tramitar unas boletas de sanidad que garantizaran su estado de salud. Muchas de estas medidas contaban con una larga tradición, ver GAVALDÁ, Francisco (1651), Memoria de los sucesos particulares de valencia, y su Reino. Valencia, Silvestre Espassa (París-Valencia, Ed. facsímil, 1979). En el Cap. III que trata de como «Padecen de contagio algunos lugares del Reyno, y Valencia guarda sus puertas», afirma: «No se dejaba entrar a persona alguna de fuera la ciludad que no mostrase boletín del lugar de donde venía, y registrado de todos los lugares por donde pasaba; de mano del cura, justicia, o jurados del lugar». Estas medidas tomadas en Valencia con motivo de la epidemia de peste padecida en 1647-48, vuelven a utillizarse en 1804, en Alicante con la epidemia de fiebre amarilla; AMA. Sanidad. Legajo 1, $\mathrm{n}^{\circ}$ 2. Alicante, 17 de enero de 1805. Carta de Manuel Mirallas. Dicha boleta tenía que estar firmada por la justicia o cura párroco del pueblo de origen o, si pertenecía a un partido, del diputado del mismo y debían llevar en caso de ir a vender frutos, incluida la respuesta del justicia del pueblo al que se dirigían.

15. AMA. Sanidad. Legajo 1, n 5. En AHO. FM. D. 1.239, n 13, Carta del Sr. Betegón a los Sres. del ayuntamiento de Orihuela, fechado en Alicante a 16 de septiembre de 1804, se indica: «oy quedará establecido el correspondiente Lazareto y trasladados a él los enfermos...»; Noticias sobre el lazareto establecido en el convento de San Francisco y otro establecido en el denominado de los «Ángeles»: Diario de Alicante, 15/XI/1927.

16. AMA. Sanidad. Legajo $1, n^{\circ} 8$ bis. Carta de don Antonio Martínez fechada en Madrid a 2 de octubre de 1804, dirigida al gobernador Betegón. En esta carta el señor Martínez aboga por su hermana, resi- 
epidemia, el puerto y la fábrica de cigarros de la ciudad fueron cerrados también, ${ }^{17}$ quedando privados de su jornal una numerosa parte de la población alicantina.

\section{RECHAZO DE LA POBLACIÓN A LAS MEDIDAS DE AISLAMIENTO IMPUESTAS POR LAS AUTORIDADES}

A propósito de la resistencia de la población frente a las medidas de cuarentena, el comandante Buck envió al gobernador Betegón el 26 de octubre de 1804 una carta donde indicaba:

«Me hago cargo de la resistencia a la cuarentena y no me admira, porque por aquí son de tal especie que si se les dejara, todos se irían a ver [a] los contagiados [...] Los tengo por unos bárbaros y protectores de todos los males». ${ }^{18}$

La población rechazaba tales medidas de aislamiento que además suponían la pérdida del salario durante los días impuestos. Sin embargo, no dejaban de adoptar ciertas precauciones para resguardar su salud, pues cuando fueron destacadas en Elche y Orihuela algunas tropas del regimiento de América que, con anterioridad, habían estado en Málaga mientras reinaba la epidemia de fiebre amarilla, la gente huía de estos soldados y no se encontraba en el pueblo quién quisiera alojarles en sus casas. ${ }^{19}$ Uno de los graves problemas que las autoridades tuvieron que abordar durante la epidemia fue hacer cumplir a los vecinos insolventes la máxima de aislamiento. La desigualdad ante la enfermedad y la muerte es un hecho evidente, ${ }^{20}$ y tanto más evidente cuanto menores son los recursos y mayor la gravedad de la situación. Ambos factores estuvieron presentes en la epidemia de 1804 en Alicante.

El aislamiento, cuando aparecía un enfermo de fiebre amarilla, podía efectuarse de diversas maneras. Las personas que poseían medios económicos, en general, emigraron a las casas de campo de los alrededores, y caso de presentarse enfermos, de-

dente al parecer en Alicante y viuda recientemente por la muerte de su marido, y solicitaba permiso para que pudiera salir de la ciudad con sus hijos a una casa de campo y librarse del peligro. Se lamentaba de que a pesar de su extremada pobreza se le afligiera con dos guardias a la puerta, debiendo pagar «dos pesetas diarias a cada uno». En Diario de Alicante, 15/XI/1927, se informa de la habilitación de casas para los enfermos convalecientes en las inmediaciones de la ciudad, así como de la hacienda de las Balsas que se utilizó de lazareto de convalecencia para los primeros enfermos de la calle Mayor que consiguieron sobrevivir. Sobre los lazaretos llamados de barracas: RANM. Fol. 8, leg. 20, doc. 1156. Observaciones... 22/V1/1816, se observa el hecho de que en estos lazaretos de barracas, a pesar de ser el enfermo asistido por sus familiares y haber morado en la misma barraca, nunca se propagó el contagio.

17. Diario de Alicante, $16 / \mathrm{XI} / 1927$ y 18/XI/1927. Noticias sobre el cierre a finales de septiembre del puerto de Alicante y el 15 de octubre de la fábrica de cigarros.

18. Diario de Alicante, 8/XII/1927. El comandante Buck, se encontraba en Elche, por lo que cuando dice «por aquí» suponemos se refiere a esa localidad y alrededores.

19. Diario de Alicante, $8 / \mathrm{XII} / 1927$. No se especifica la fecha.

20. Esta desigualdad social ante la enfermedad y la muerte es abordada en numerosos estudios de diferentes epidemias. Entre ellos: CARRILLO, J.L; GARCÍA BALLESTER, L. (1981), op.cit., pp. 49-51 y 80-83 especialmente. BERNABEU MESTRE, J; PERDIGUERO GL, E. (1994), op.cit., pp. 92, 94; BERNABEU MESTRE, J.; RAMOS SEGURA, J.R. (1995), op. cit., pp. 216-220; EVANS, R.J., (1987), op. cit., pp. 158-159. 
bían pagar a dos guardias continuos que se apostaban a la puerta para garantizar que el aislamiento se cumplía. Corrían además con los gastos médicos, la manutención de los moradores de la casa y los gastos de las fumigaciones. En contraposición, cuando aparecía un enfermo en una familia humilde, la denuncia del mismo a las autoridades comportaba mandarlo al lazareto de curación, el cual, como tendremos ocasión de comentar, presentaba unas condiciones lamentables; el resto de la familia era sometida a cuarentena, la casa clausurada, parte de sus bienes quemados y, si no eran indigentes, los pocos recursos que poseyeran debían dedicarlos a pagar fumigaciones y remedios de dudosa eficacia. Por estas razones, la mayoría de la población ocultaba sus propios enfermos. El médico Ambrosio Lorite, enviado por la Junta Suprema de Sanidad como director de la epidemia declarada en Alicante, denunció estos hechos:

«Desde mi llegada a esta ciudad no he parado de clamar para que se haga una requisa de todo el pueblo, casa por casa». ${ }^{2 i}$

Dicho médico propuso que los comisarios y alcaldes de barrio, junto con el médico correspondiente, confeccionasen una lista de los enfermos existentes en la ciudad. ${ }^{22}$ Debía realizarse una «requisa prolixa», enviar a los enfermos al lazareto y fumigarse todo lo infecto, como remedios para frenar cuanto antes el contagio. ${ }^{23}$ Como declararon posteriormente los mismos médicos de Alicante:

«La repugnancia de ir al Lazareto era la causa de que muchisimos enfermos se ocultasen, y no llamasen al médico; y estos abandonados a la suerte tenían el [mismo] resultado que los más bien asistidos... ${ }^{24}$

Los médicos eran los primeros por tanto en reconocer su propia incapacidad para curar la enfermedad reinante, por lo que parece lógico que los familiares prefirieran cuidar en sus propios hogares de sus enfermos. Como ya comentamos, el lazareto de curación se instaló en el convento de los Padres Franciscanos. Según el médico Lorite, a su llegada se encontraba «enteramente perdido sin asistencia ni medicina». Ante la negativa de los vecinos de atender voluntariamente a los enfermos, fueron obligados seis presos que se encontraban condenados en las obras del muelle. ${ }^{25}$

Diversas declaraciones del contralor del lazareto, Falomir, ilustran el ambiente que debía reinar en el mismo promovido en gran parte por los presos utilizados como enfermeros:

«Siempre es mover algarabia y robar cuanto pueden [...] después de ser la gente más soez del pueblo, y que muchos de ellos se hallan aquí no porque su corazón les ha movido, sino por libertarse de aquellas penas en que estaban procesados $[. .$.$] No siendo$

21. Diario de Alicante, 19/XI/1927.

22. PALAZÓN AZORÍN, José María, (1977), La epidemia de fiebre amarilla de 1804 en la ciudad de Alicante, Valencia, Tesis de licenciatura presentada en la Facultad de Medicina de la Universidad de Valencia, inédita. Cita el documento: Carta de D. Ambrosio Lorite..., 25-X-1804.

23. PALAZÓN AZORÍN, José María, (1977), op.cit. Cita el documento: Carta del director de la epidemia..., 28-X-1804.

24. RANM. Leg. 20, doc. 1.156, fol. 8. Observaciones...

25. Diario de Alicante, 15/X1/1927. Declaraciones del coronel Fulgosio, nombrado en septiembre director del lazareto, renunciando poco después. «pues por más ventajas que he proporcionado a los paisanos de este pueblo para que concurriese a este servicio ninguno quiso aceptar». 
bastunte castigo el ponerles en el cepo he tomado otro método que es suspenderles el sueldo de aquel dia.» ${ }^{26}$

El lazareto se llenó de enfermos, y según declaraciones de los mismos padres franciscanos el número de ellos no había bajado de $300 .{ }^{27}$

El cordón sanitario establecido alrededor de la ciudad también era motivo de un fuerte rechazo por parte de la población. A poco de comenzar la epidemia, a mediados de octubre, ocurrió un incidente en el mismo, en uno de los puntos que se acordaron para la celebración del mercado que facilitaba el abastecimiento de la población encerrada por el mismo. En el lugar conocido como el «montecillo de la Cueva del Guijarro» en la villa de Tibi, después de celebrado el mercado, se presentaron hombres armados y capitaneados por un fraile observante de la orden de San Francisco, llamado Fray Rico de Monóvar, que intimidaron al guardia paisano para que retirara el cordón y las cuerdas y, ante su negativa, los mismos hombres armados las retiraron. Este hecho fue comunicado a las autoridades y calificado de muy grave, pues además de la insubordinación y desobediencia, permitió que algunas personas burlaran el control y escapasen del cerco marcado. ${ }^{28}$ La mayoría de las personas carecían de recursos y los precios se elevaron considerablemente durante los meses de epidemia, provocando disturbios entre el público y los vendedores que acudían a los mercados que se celebraban en los puntos establecidos del cordón. ${ }^{24}$ Cartas cruzadas entre el gobernador Betegón y el comandante don Pedro de Buck, traslucen estas complicaciones que surgían alrededor del cordón sanitario. Se recibieron quejas de alborotos, de insultos, de gentes que «buscan roce». ${ }^{30}$ La población sometida a aislamiento no cumplía las órdenes de evitar rigurosamente el roce con las poblaciones sanas y, a su vez, los cordones tampoco evitaban eficazmente el paso de las personas de unos lugares a otros, pues en una carta que el comandante envió al gobernador comentaba, a propósito de haberse contagiado la localidad de San Juan:

«Yo no lo extraño ni tampoco que se pegasen, desde luego, por el roce que despreciaron esas gentes a pesar de las providencias que vuesa merced dió: parecen idiotas.»"

Tampoco colaboraba la población alicantina en el problema del contrabando, que era considerado causa del inicio de muchas epidemias y fuertemente perseguido y castigado. Sin embargo, para los habitantes era una fuente de ingresos, sobre todo en épocas de crisis económicas, y contaba en gran parte con la simpatía de la mayoría de los vecinos de nivel económico bajo. Esta afirmación puede deducirse del hecho de que tuviese que ofrecerse una recompensa para conseguir que se denunciase. Las personas dedicadas a esta actividad solían habitar en los arrabales de San Francisco y en el Raval Roig, entre marineros que supuestamente serían sus cómplices en la ocul-

26. Diario de Alicante, 15/Xu/1927.

27. Ibidem.

28. AMA. Sanidad. Legajo 1, $\mathrm{n}^{\circ} 7$ bis. Carta de Pedro Buck al Sr. Betegón. Elche, 17 de octubre de 1804.

29. Diario de Alicante, 14/XI/1927.

30. Ibidem.

31. Diario de Alicante, $8 / \mathrm{X} 1 / 1927$. En el periódico no se especifica la fecha en que dicha carta fue enviada. 
tación del delito. En plena epidemia fueron rechazados los buques contrabandistas a fuego de cañón. Así se revela en un oficio del comandante Buck en el que hacía referencia a los lugares de Santa Pola, Albufereta, Carabasí y Arenes Groses, parajes cercanos a la ciudad de Alicante. Se solicitó que los buques de guerra persiguieran a los de contrabando hasta hundirlos. ${ }^{32}$

El mismo gobernador de Alicante en el sumario que se le ordenó realizar en busca del origen del contagio confesaba la existencia del mismo:

«Si bien no parece comprobado que a esto se deba [a la introducción de fardos de contrabando en la ciudad] el origen de la epidemia, porque no es fácil en un pais donde son muchos los que protegen el contrabando.» ${ }^{33}$

Las medidas de represión en el cordón fueron endureciéndose conforme avanzaba la epidemia. Los soldados trataban de evitar cualquier posibilidad de fuga de las personas encerradas por el mismo. Todos aquellos que cometieran infracciones de las disposiciones sanitarias eran castigados con dureza. El robo de ropas de los fallecidos fue castigado con la muerte. ${ }^{34}$ Los que atravesasen el cordón serían castigados con pena de diez años de trabajos forzados en las obras del muelle más doscientos azotes. ${ }^{3.5}$ En el lazareto hubo varias evasiones. No es extraño que los que vivían más de cerca el horror de la fiebre amarilla intentasen huir del cerco con más empeño. EI presidiario Juan Coves, apodado Trentaden, provocó varios altercados. Tras conseguir escapar y ser detenido y devuelto al lazareto, volvió a evadirse limando los grillos que le apresaban y desapareció de la ciudad. El gobernador decretó que, en cualquier parte donde fuera detenido el presidiario Coves, se le pasara por las armas. ${ }^{36}$

También en octubre otro presidiario llamado José García, conocido por Sandinga, se evadió del lazareto, ${ }^{37}$ atravesó el cordón sanitario y vagó por los campos, hasta que una partida armada de paisanos y de varios húsares de Numancia lo reconocieron y lo detuvieron en los alrededores de Elche, donde fue fusilado. El comandante Buck informó del hecho al gobernador Betegón en los siguientes términos:

"A las diez de la mañana [del 19 de octubre] y a media legua distante de Elche, ha sido pasado por las armas José García, alias Sandinga, desertor del lazareto [...] con to que se tiene ese perverso menos en el Estado.» ${ }^{\text {* }}$

32. Diario de Alicante, 20/XIV/1927. Se hace referencia a un oficio de Buck del 26 de octubre de 1804 .

33. Diario de Alicante, 20/XII/1927.

34. Diario de Alicante, 24/XI/1927. Unos carreteros encargados de la «quema y saca de cadáveres», robaron las ropas de los fallecidos. Preguntado Betegón sobre la pena que les cabía al parecer ordenó que fueran pasados por las armas. No hay en el AMA documentos que corroboren dicha información, pero si hemos de creer al autor de estos artículos que trabajaba en el mismo, pudo haberlos habido.

35. Ibidem.

36. Diario de Alicante, 24/XI/1927. AMA. Sanidad. Legajo 1, nº 7 bis. Carta del gobernador Betegón al Sr. Pedro de Buck y O’Donell, fechada en Alicante a 18 de octubre de 1804. Le enviaba la orden para la captura de Juan Coves, de la que había realizado varios ejemplares y hecho circular por algunos pueblos

37. Diario de Alicante, 25/XI/1927.

38. Ibidem. 
Las deserciones continuaron a medida que aumentaban los horrores de la epidemia. ${ }^{39}$ En diciembre de 1804, cuando la epidemia ya remitía, las evasiones siguieron produciéndose a pesar de la severa vigilancia a que la ciudad era sometida.

Otras medidas de aislamiento adoptadas para prevenir las epidemias y su extensión eran las llamadas de sanidad marítima. Ya en 1803 se tomaron en el puerto de Alicante las medidas conducentes a garantizar la salud de la población. Aquellos barcos que procedían del puerto de Málaga, donde reinaba una epidemia de fiebre amarilla, no se admitían en la bahía de Alicante y eran desviados hacia otros puertos. El comercio de la ciudad, cuyos mayores intereses arribaban por el mar, se vio perjudicado y elevó una queja al gobernador como presidente de la Junta de Sanidad solicitando que, sin pretender evitar la cuarentena preceptiva que los buques debían realizar, se les informase del paradero de sus mercancías para no verse alteradas sus actividades comerciales y se les procurase la hospitalidad precisa a estos barcos en el paraje más a propósito. ${ }^{40}$ Una de las medidas adoptadas fue la de ordenar a los buques que se encontraban en el puerto de Alicante con anterioridad a la declaración oficial de la epidemia que permaneciesen anclados. ${ }^{4}$ Sin embargo, en la madrugada del día 11 de octubre se hicieron a la vela la polacra otomana San Nicolás y la rusa Madona Juliana que habían llegado antes del cierre del puerto con cargamentos de trigo. Dichas polacras huyeron sin tener la patente de Sanidad, acto que, en tiempos de epidemia, estaba castigado con la pena de muerte para sus capitanes. Agravaba la situación el hecho de que sus tripulantes hubieran saltado a tierra todos los días, aun aquellos en los que la epidemia había sido más intensa. Enterado del incidente, el gobernador lo comunicó al gobierno central junto con el estado de confusión y desorden en que se encontraba la ciudad. El conde de Montarco contestó ordenando, para evitar sucesos similares, que hiciese recoger los timones de todos los barcos anclados en el puerto. ${ }^{+2}$

Las medidas de aislamiento adoptadas también supusieron graves pérdidas para el pequeño comercio de la ciudad que se vio alterado con motivo de la epidemia. A este respecto se declaraba en 1805 :

«de consiguiente rebaxó enormemente la concurrencia de arrieros, y demás que se ocupan en la venta de comestibles, cesando después enteramente el tráfico de la plaza por las muertes de una multitud de personas, y por hallarse otras enfermas, cerradas absolu-

39. Sobre las evasiones durante la epidemia se dan noticias en el Diario de Alicante, 25/XI/1927, aunque debe resaltarse que en el AMA no se han encontrado documentos al respecto. Al parecer se apresó también a Pascual Martínez y a Cristóbal García, que en el paraje llamado de Agua Anarga habían atravesado el cordón. También del lazareto huyó una sirvienta de nombre Vicenta «la Pardaluda». Un soldado del regimiento de América saltó la muralla, por la parte de San Antón, siendo capturado días después en Callosa. El 7 de diciembre Andrés Martínez, junto a un sujeto de Elche llamado Juan Santá, atravesaron el cordón sanitario. Según el parte que informaba de este hecho, Juan Santá llevaba consigo «una mantilla de su mujer que poco ha murió. Quién también ha confesado deja dentro del término de Alicante un arca con ropa y cerca de mil reales». También atravesaron el cordón sanitario un soldado, llamado José Blanc, y un cazador de nombre Nicolás Grife.

40. AMA. Sanidad. Legajo 1, n 4 bis. Carta fechada en Alicante a 2 de noviembre de 1803, de Francisco Morales y Juan Bautista Antoine, dirigida al gobernador don Josef de Sentmanat.

41. Diario de Alicante. 19/XI/1927.

42. Ibidem. 
tamente las comunicaciones [...] es una consecuencia precisa de la dolorosa calamidad que ha sufrido el pueblo, y sentirá por algunos años respecto a la decadencia que ha influido en el comercio, $y$ tráfico... ${ }^{43}$

\section{CONSECUENCIAS SOCIO-ECONÓMICAS PROVOCADAS POR LAS MEDIDAS POLÍTICO-SANITARIAS}

Desde el comienzo de la epidemia una de las preocupaciones del gobernador fue cubrir los gastos que la misma ocasionaba a las economías menos solventes de la ciudad. Conforme la epidemia se prolongó, los gastos ocasionados y las personas afectadas aumentaron. Ya en octubre de 1804, don José Betegón comunicaba que se atendía con 500 reales diarios a los pobres y a los enfermos, con raciones de pan y carne y «procuro buscar medios de aumentar este preciso auxilio, como que diariamente se ve que progresa la pobreza». ${ }^{\text {th }}$

El aprovisionamiento de la ciudad durante la epidemia se dificultó al cerrarse el puerto de Alicante. Para paliar esta medida, y posibilitar la llegada de las embarcaciones, se habilitó el puerto de Torrevieja para «la introducción de granos extranjeros y extracción de frutos nacionales» y desde el día 16 de octubre de 1804 se autorizó dicho puerto para importar toda clase de comestibles, nombrándose un fielato dependiente de Alicante, bajo la intervención de don Antonio Hidalgo, administrador de las salinas de La Mata para el embarco de mercancías. ${ }^{45}$ A pesar de estas disposiciones, la falta de víveres y de dinero fue agravándose progresivamente durante el transcurso de la epidemia, provocando la crispación de la población, lo que hacía insostenible la prolongación del aislamiento como demuestran algunos testimonios. A finales de 1804, cuando ya se daba por concluida la epidemia, una carta instaba a que el gobernador abriera la comunicación de la ciudad, pues «son repetidas las expresiones que han sido oílas a las gentes y temen algún atropellamiento». ${ }^{\text {to }}$ La comunicación de la ciudad no podía restablecerse sin realizar antes las pertinentes fumigaciones, cuya orden de inicio debía darla el capitán general del Reino de Valencia. Dicha orden se hizo esperar por lo que Betegón durante todo enero manifestó su preocupación por el estado de crispación de la población. El 9 de enero de 1805, escribía a don Domingo Izquierdo:

"los males actuales, de este pueblo, son los de la miseria de muchos pobres que en su semblante manifiestan la necesidad y falta de alimento, sin recursos para socorrerlos, pues sólo se dan diariamente de limosna 700 reales que no alcanzan a cuxiliar la quarta parte $[. .$. . no es de extrañar los continuados clamores por la abertura del puerto y de la fábrica de cigarros, y si no se verifica lo uno y lo otro concluida la quarentena rigurosa

43. AMA. Correspondencia. Legajo 4, n' 63. Carta de Joseph Pina, fechada en Alicante a 2 de mar\%o de 1805.

44. AMA. Sanidad. Legajo $1, n^{\circ} 8$ bis. Carta del Sr. Betegón al obispo de Orihuela, fechada en Alicante a 18 de octubre de 1804.

45. PALAZÓN AZORÍN, José María, (1977), op.cit. Se hace referencia a [Real Orden por lo que se habilita], 16-X-1804. Este documento no lo hemos conseguido encontrar entre los revisados en el AMA.

46. AMA. Sanidad. Legajo I, $n^{\circ} 4$, h. 2. Carta sin fechar y sin firmar, pero por el contenido posterior al 25 de diciembre de 1804. 
serán maiores sus clamores, que podrán pasar a algún exceso, y más quando faltan ya los medios para continuar la limosna. ${ }^{17}$

El doctor en medicina de la Facultad de Montpellier don Auguste Lemosy, enviado a estudiar la epidemia por el consejo de propios del partido de Montpellier, declaró el 1 I de enero de 1805 que hacía 40 días que no había ningún caso, no obstante haber cerca de 2.000 personas en la ciudad que no habían padecido la fiebre amarilla. Aseguraba este doctor que el mayor problema de la población consistía en la «inacción» por hallarse aislada, como consecuencia de la epidemia, por lo que urgía el restablecimiento del comercio, principal ocupación y recurso de sus habitantes. ${ }^{48}$

Si en la ciudad de Alicante la población sufría todo tipo de carencias, lo mismo sucedía en otras poblaciones afectadas por la epidemia reinante. Fue el caso de los vecinos de Peñacerrada, quienes pasaban por una situación crítica a comienzos de 1805 a resultas de la cual varios vecinos pidieron auxilio al gobernador, quien solicitó al marqués de Beniel y Peñacerrada que prestara ayuda a las familias necesitadas mientras concluyeran las operaciones de fumigación y se normalizaba la situación. ${ }^{49}$ Debido al contagio, varios de los vecinos de Peñacerrada abandonaron el pueblo y sus casas y se marcharon al campo, en chozas o barracas, donde permanecieron más de 60 días, hasta que pasaron los «prácticos de la ciudad y perfumaron» las casas, ${ }^{50}$ volviendo entonces al pueblo. A primeros de enero todavía se hallaban acordonados, Io que confesaban les era indiferente siempre que tuvieran con que alimentarse, pero temían morir de necesidad si no se les permitía salir a ganar el jornal con el que alimentar a los niños. Solicitaban al gobernador ayuda o en su caso realizar la cuarentena que les ordenaran en la villa de Muchamiel. La situación en enero era insostenible y el gobernador temía una revuelta de la población provocada por la miseria, a consecuencia de la falta de trabajo y jornal y el hambre sobre todo de los niños, máxime cuando ya no existían casos de fiebre amarilla en la misma y faltaban recursos con los que hacer frente a esta situación. ${ }^{\text {s1 }}$ En este sentido el día 13 de enero de 1805 , el cura Juan Antonio Costa escribió al gobernador comunicándole:

47. AMA. Sanidad. Legajo 1, n 17, b. 6. Carta del Sr. Betegón al Sr. Izquierdo, fechada en Alicante a 9 de enero de 1805 .

48. AMA. Sanidad. Legajo 1, n ${ }^{\circ}$ 16, h. 1. Carta de Auguste Lemosy al gobernador de Alicante, fechada en Alicante a 11 de enero de 1805 .

49. AMA. Sanidad. Legajo 1, n 5, h. 3. Carta del Sr. Betegón al marqués de Beniel y Peñacerrada, fechada en Alicante a 6 de enero de 1805.

50. AMA. Sanidad. Legajo 1, $n^{\circ}$ 5, h.2. Carta de Josep Lledó al gobernador, fechada en Peñacerrada a 9 de enero de 1805. Sobre Peñacerrada también: AMA. Sanidad. Legajo 1, n 2, h. 8. Carta del Sr. Betegón al Sr. Mirallas, fechada en Alicante a 12 de enero de 1805. El propio diputado de Peñacerrada, comunicó al gobernador que los hijos de los vecinos de aquella población se morían de hambre. AMA. Expedientes y Veredas. Arm. 15, Lib. 36. Fol. 501. Carta de Fco. Sala y Cantó, fechada en Peñacerrada a 31 de enero de 1805. Después del contagio quedaron en Peñacerrada 17 vecinos, de los cuales cuatro eran viudas. Al respecto en 1804, según RICO-AVELLÓ y RICO, C., (1953), Fiebre amarilla en España. Epidemiologia histórica, Madrid, p. 51, existían en Peñacerrada 100 habitantes y señala 14 defunciones, por lo que el resto de vecinos suponemos habría emigrado. En esta pequeña población no existirían comerciantes ni hacendados que hicieran frente a una situación de epidemia como la que se sufrió, con excepción del marqués de Beniel.

51. AMA. Sanidad. Legajo 1, $11^{\circ}$ 2, h. 8. Carta del Sr. Betegón al Sr. Mirallas, fechada en Alicante a 12 de enero de 1805 . 
«Mui Sr. mío, me acaban de abisar, como a cura párroco y con la debida reserba para que lo haga saber a V.S., que algunas gentes de este pueblo quieren en el día 17 de este mes presentarse en el Ayuntamiento, para pedir, y obtener (si fuese negado) con violencia, la abertura del puerto, y conclusión de quarentena, y que para llebarlo a efecto, tenían algunas prebenciones; no sé si será así como me lo han comunicado, pero de qualquier modo juzgo que por mi oficio debo hacerlo presente a V.S. con la maior reserba, para que en tiempo pueda tomar las disposiciones que juzge oportunas para evitarlo. ${ }^{52}$

Los esfuerzos por evitar el contagio de este tipo de enfermedades y las medidas preventivas de fumigación también provocaron a menudo pérdidas económicas y conflictos en la población alicantina. Tenemos noticias de que al menos un barco fue quemado por haber fallecido tres de sus pasajeros durante la travesía de una enfermedad sospechosa de ser la fiebre amarilla. ${ }^{53}$ El 8 de enero de 1805 el gobernador escribió al conde de Montarco remitiéndole un escrito de los cónsules de Alemania, Dinamarca y Suecia en el que solicitaban que no se fumigasen las embarcaciones de sus respectivas naciones, que se hallaban en el puerto de Alicante desde antes de declararse el contagio, alegando que no había habido ningún enfermo de fiebre amarilla en los mismos y que de practicarse dicha operación perjudicaría en gran manera al comercio y contradiría los avisos dados de haber estado sano el puerto. Alegaban que en Málaga se realizó la fumigación de los buques porque en ellos se había padecido el contagio. Habiendo sido consultado el médico Lorite, éste autorizó que no fueran fumigados por las razones anteriores. ${ }^{54}$

Finalmente, en octubre de 1805 un bando informó del fin de las prevenciones para evitar un nuevo rebrote de fiebre amarilla y la celebración del Te Deum de acción de gracias, según Real Orden recibida, y se hacía un llamamiento a la generosidad de los vecinos pudientes hacia aquellos que debido a la enfermedad se encontraban sumidos en la miseria. ${ }^{55}$

52. AMA. Sanidad. Legajo 1, n 4, h. 1. Carta del cura Juan Antonio Costa al Sr. Betegón, fechada en Alicante a 13 de enero de 1805.

53. AMA. Correspondencia. Legajo 4, $\mathrm{n}^{\circ}$ 1. Carta de D. José Betegón al conde de Montarco, fechada en Alicante a 8 de enero de 1805 . Comunicación al rey del 16 de octubre de 1804, en la que se informa que la Junta de Sanidad había resuelto la quema de un barco español, procedente de Gibraltar, que varó en las playas alicantinas, habiendo fallecido durante la travesía tres pasajeros. Aclaraba el escrito «siendo probable fuese de resultas de las enfermedades epidémicas que se experimentan en aquella plazar.

54. AMA. Correspondencia. Legajo 4, $\mathrm{n}^{\circ}$ 1. Carta de D. José Betegón al conde de Montarco, fechada en Alicante a 8 de enero de 1805 .

55. AMA. Sanidad. Legajo $1, \mathrm{n}^{\circ}$ 22. Bando de D. Josef Betegón, comunicando la Real Orden del 26 de septiembre de 1805, sobre eliminación de cordones y celebración del Te Deum. Fechado en Alicante a 9 de octubre de 1805. Un ejemplo de la trágica situación que este tipo de enfermedades epidémicas provocaba, junto a las medidas de aislamiento impuestas, lo constituye un documento de 1821 relativo a las epidemias de fiebre amarilla declaradas en Mallorca y Tortosa: AMA. Sanidad. Legajo 1, $n^{\circ} 59$. Manifiesto de la Junta Superior de Sanidad de la Provincia de Valencia, fechada a 25 de septiembre de 182 I y enviada a la Junta municipal de Sanidad de Alicante para promover el socorro de los habitantes de Mallorca y Tortosa, afectados de suna fiebre contagiosa [...] y sin analogía íntima con la fiebre amarillas. Aunque en estos momentos se negaba que la enfermedad se tratara de la fiebre amarilla, posteriormente se confirmó «doloroso ver a las Autoridades de Mallorca rodeadas de amargura [...] y triste en fin la posibilidad de que sobre el azote del contagio, experimenten también el de la hambre, 


\section{DIFERENTES COMPORTAMIENTOS DURANTE LA EPIDEMIA}

Entre los hacendados y nobles de Alicante se encontraban en 1804 el marqués de Castel-Rodrigo, don Francisco y doña Luisa Valcárcel, el barón de Finestrat, los marqueses del Bosc, Río Florido, Beniel y Peñacerrada, los condes de Soto Ameno y Bolaños, doña Francisca Sarrió, la viuda de Salvador Pobil, los señores Rovira, Gamborino, Marbeuf, Ansaldo, don Miguel Bonanza y otros. ${ }^{56}$ En cuanto comenzaron las sospechas del contagio, las personas que pudieron, comenzaron a huir de la ciudad:

«declarándose contagio en trece de septiembre, por cuya causa huvieron de salir y salieron arrebatadamente de la propia ciudad y arravales la parte más pudiente del vecindario, títulos de Castilla, toda la nobleza, comerciantes, el mayor número del cabildo eclesiástico y otros ciudadanos. \$7 $^{57}$

Las personas que quedaron en la ciudad por obligación o por imposibilidad de abandonarla, no condenaban la emigración, siempre que el hacendado no se tratara de un regidor como veremos más adelante, pero una vez a salvo del peligro de la epidemia, cuando se les solicitó ayuda económica para hacer frente a la situación, defraudaron las expectativas de todos aquellos encerrados por el cordón sanitario y que contaban con su auxilio. Apenas comenzó la epidemia de fiebre amarilla se iniciaron los problemas económicos. Del gobierno central no cabía esperar grandes ayudas ya que carecía de fondos. ${ }^{58}$ En octubre de 1804 , se obligó a los comerciantes y a los hacendados alicantinos a contribuir a los gastos de la epidemia, según sus posibilidades. ${ }^{5}$ Así lo comunicó el conde de Montarco a la Junta de Sanidad de Alicante:

"Por la carta de V.S. de 17 del corriente y estados que acompaña se ha enterado la Junta Suprema de Sanidad [...] como igualmente de la falta de fondos con que se halla para atender a los gastos que son indispensables; por lo qual ha dispuesto repartir medio millón de reales entre el comercio y hacendados [...] teniendo presente que no se puede contar por ahora con mayor caudal de los pertenecientes a S. Magestad por las muchas atenciones que exigen las circunstancias actuales»"

El 6 de octubre de 1804 el gobernador Betegón escribió al director de la casa de Bushell, uno de los comercios alicantinos, lamentándose de que a pesar del acuerdo

cuyas dos furias llevan en pos de sí la injusticia, el latrocinio, la desobediencia a las leyes, el menosprecio a las autoridades, la falta de virtudes, y todos los demás horrores de que son capaces los hombres. Aun es más deplorable todavía la situación de los pueblos inmediatos a Tortosa, que acosados de la consternación y de la miseria hasta el átimo grado de desesperación, han intentado traspasar el cordón, sino se les socorre, y entregar sus pechos a las balas y bayonetas de la tropa que quiera impedirlo».

56. Diario de Alicante, 23-XI-1927.

57. AMA. Correspondencia. Legajo 4, n 63. Carta de Josep Pina, Alicante, 2 de marzo de 1805.

58. AMA. Libro de Cabildos de 1804. Sesión de cabildo ordinario del 2-VII-1804. fol. 109. Real Orden en la que se solicitaba que los vasallos pudientes auxiliaran a S.M. con las cantidades que pudieran, a cuenta de las contribuciones del año corriente.

59. AMA. Sanidad. Legajo 1, n 1, h. 5. Carta del Sr. Betegón a don Fco. Valcárcel, fechada en Alicante a 6 de marzo de 1805.

60. AMA. Sanidad. Legajo 1, n 4, h. 3. Carta del Conde de Montarco a la Junta de Sanidad de Alicante, fechada en Madrid a 20 de noviembre de 1804. 
anterior le resultaba muy difícil reunir tal suma, «por hallarse los sugetos contribuyentes ausentes de esta ciudad», por lo que le solicitaba que facilitara el dinero que pudiera, el cual le sería posteriormente reintegrado de los caudales de la Real Hacienda o de la contribución, facilitándole las garantías precisas. ${ }^{61}$

En general fue menos problemática la contribución del comercio a los gastos de la epidemia que la de los hacendados. Para la contribución del medio millón de reales se hicieron varias partes. Para el reparto de la tercera parte del citado medio millón de reales entre los hacendados, los regidores don Ignacio Spering y don Josef Rodríguez procedieron a su distribución entre:

«aquellos sujetos que, por los conocimientos prácticos del pueblo, sabían eran capaces de aprontar las cantidades para acudir al socorro de la humanidad afligida, considerándoles no se negarian en un caso tan urgente. ${ }^{62}$

A pesar de que dicho desembolso era en calidad de reintegro con motivo del impuesto del equivalente, ni siquiera esta circunstancia promovió la generosidad de la mayoría de los hacendados alicantinos. ${ }^{6.3}$ El gobernador recurrió a enviar cartas personales a los diferentes interesados, apeló a la generosidad, al bien de la patria, a la misericordia y al amor a la humanidad y a los pobres. También recurrió al chantaje, prometiendo recomendaciones personales como mérito por el auxilio «a su patria y hermanos que se hallan [en] extrena medida afligidos». ${ }^{\text {it }}$ Sin embargo, la mayoría de los hacendados y regidores procedieron de manera cobarde o egoísta.

Los regidores tenían la obligación de permanecer en la ciudad y encargarse de los oficios que les habían correspondido en relación a dicha actividad. Al comenzar 1804 había falta de regidores, pero además la emigración de algunos de ellos agravó la situación. A mediados de septiembre, cuando el cabildo municipal y la Junta de Sanidad se refugiaron en el aula capitular de la parroquial iglesia de Santa María, ${ }^{65}$ el número de regidores era insuficiente para atender las medidas que debían adoptarse. El día 19 de septiembre, el regidor Burgunyo, de la clase de nobles, se encontraba enfermo y ausente, así como el señor Phelipe Tomás; el señor Sanmartino, comisario además de Sanidad, se encontraba en cuarentena; el señor Muñoz se retiró poco antes de comenzar el cabildo enfermo. También el secretario don Tomás Pro estaba enfermo. El gobernador, tres regidores ${ }^{66}$ y el síndico personero, realizaron la sesión de cabildo.

61. AMA. Sanidad. Legajo 1, n 8 bis. Carta del gobernador Betegón al Sr. Director de la casa de Bushell. Fechada en Alicante a 6 de octubre de 1804.

62. AMA. Sanidad. Legajo 1, n 1, h. 4. Carta del gobernador Betegón al Sr. Fco. Valcárcel. Fechada en Alicante a 7 de marzo de 1805 .

63. AMA. Sanidad. Legajo 1, n 1, h. 1. Carta de Betegón al Sr. Fco. Valcárcel Pío de Saboya, fechada en Alicante a 8 de noviembre de 1804. Las cantidades asignadas debían entregarse en la tesorería del Consulado de Alicante, o a don Eugenio Ferrer, persona que se encargaba de ello.

64. AMA. Sanidad. Legajo 1, $n^{\circ}$ 1, h. 1. Carta de Betegón al Sr. Fco. Valcárcel Pío de Saboya, fechada en Alicante a 8 de noviembre de 1804. En esta carta de Betegón, respuesta a otra del Sr. Valcárcel en la que parece que alegaba imposibilidad de pagar los 13.000. reales de vellón que le habían correspondido, Betegón apela a todos los sentimientos para lograr el pago, que no obstante no logra.

65. AMA. Libro de Cabildos de 1804. Fol. 160v. Sesión extraordinaria del 19 de septiembre.

66. Ibidem. Los regidores eran Marquina, Navarro y Pérez Savater. 
Emigraron los regidores don Juan Antonio Aguilar, don Felipe Tomás, don Pedro Burgunyo y don Vicente Navarro. El regidor don Pedro Burgunyo ni siquiera llegó a incorporarse a su cargo. Poseía un permiso para ausentarse de la ciudad concedido con anterioridad a la fecha de declaración de la epidemia, el 13 de septiembre de 1804. ${ }^{67}$ Posteriormente se declaró la epidemia y ya no se incorporó a su cargo.

Por su parte el regidor don Felipe Tomás, según declaraciones del propio gobernador Betegón, se ausentó antes del contagio habiéndole pedido permiso «de que no usó hasta pocos días antes de declararse [la epidemia]». Habiéndosele pasado oficio para que regresase a servir su empleo después de declarada la epidemia, envió certificaciones de «físicos», pero no se incorporó. Una vez abierta la comunicación de la ciudad y acabada la epidemia, dicho regidor pretendía que se le concediera el cargo de regidor jubilado con Real Cédula de preeminencia, con salario y emolumento, tal como había gozado el fallecido regidor don Pablo Salafranca. Se discutió entre los regidores la conveniencia o no de esta solicitud y todos ellos hicieron constar, en las actas de la reunión del cabildo, que se oponían por el incumplimiento del deber en que había incurrido dicho regidor y por ser el número de regidores ya insuficiente para el desempeño de los empleos a cubrir. ${ }^{68}$

En cuanto al regidor don Vicente Navarro, éste emigró después de iniciarse la epidemia. En marzo de 1805 envió un memorial en el que solicitaba su reintegro a la abogacía consistorial y explicaba las razones de su emigración que justificaba por motivos de salud y por su avanzada edad, además de haber enfermado sus sirvientes a quienes hubo de trasladar al lazareto, no teniendo su mujer y él quién les cuidase y no habiendo sido posible hallar quién lo hiciese. No obstante aportaba como mérito el haberse encargado de las calles donde se inició la epidemia, que fueron donde más se prolongó y donde más estragos causó, hasta que debido a su deteriorado estado, en una de las reuniones diarias de la Junta de Sanidad, se le envió a casa a restablecerse y, por consejo médico, salió de la ciudad junto a su mujer para evitar la muerte por la enfermedad o por falta de cuidados. Previamente a su huida el regidor había solicitado al gobernador permiso para ausentarse pero le fue denegado. ${ }^{67}$ No sabemos si se le disculpó a este regidor su emigración, pero en todo caso su testimonio revela las duras condiciones que sufrieron aquéllos que quedaron en el interior de la ciudad, rodeados de personas cercanas enfermas, con escasez de recursos y encerradas en la población. Afortunadamente, el señor Navarro tuvo posibilidad y recursos para huir de esta situación, a diferencia de otros que por imposibilidades económicas o sentido del deber permanecieron en la ciudad, y se expusieron a la enfermedad y a todas las penalidades que la acompañaban.

67. AMA. Libro de Cabildos de 1804. Fols. 110, 144, 117v, 119v. En las actas del libro de cabildos del ayuntamiento consta que el 2 de julio Burgunyo ya debía haberse incorporado. El 13 de julio, ante su ausencia, se le requiere y el 17 de julio consta en el acta que Burgunyo ha vuelto a ser requerido. Ante estos avisos envía un certificado firmado por el médico don Tomás Bou, con fecha de 13 de agosto de 1804 , con el diagnóstico de «calenturas tercianas de la especie de pemiciosas».

68. AMA. Libro de Cabildos de 1805. Fols. 34, 34v, 38. Sesión ordinaria del 22 de febrero de 1805.

69. AMA. Libro de Cabildos de 1805. Fols, 61-62v. Memorial de don Vicente Navarro, solicitando el reintegro a lá abogacia consistorial. Fechado en Alicante a 11 de marzo de 1805. 
Otro caso que cabe citar es el del hacendado don Rafael Morant, a quien le fue concedido el título de regidor de la clase de nobles del ayuntamiento de Alicante, por fallecimiento del regidor don Pablo Salafranca, ${ }^{70}$ con posterioridad a la declaración de la epidemia, cuando ya estaban cerradas las comunicaciones con la ciudad, por lo que decidió continuar en su casa de campo, situada en el término de la villa de Elche, donde se encontraba desde junio y no se incorporó a desempeñar las tareas propias de su cargo. Pasada la epidemia, en febrero de 1805, intentó ocupar la regiduría que se encontraba cubierta interinamente con motivo de la epidemia, de acuerdo a una Real Orden que el gobernador Betegón recibió para cubrir las vacantes por muerte o emigración poco después de declararse la epidemia. Dicha solicitud le fue denegada por el cabildo municipal alegando la razón anterior. ${ }^{71}$ Respecto a su obligación de colaborar dentro de sus posibilidades en los gastos ocasionados en la epidemia a finales de abril de 1805, dos miembros del Consulado de Alicante escribieron a Betegón ${ }^{72}$ indicándole que don Rafael Morant fue uno de los vocales que, en junta celebrada el 4 de marzo de aquel año, protestó de ser elevada la contribución que le correspondía del medio millón de reales de vellón, así como de haberse realizado de forma incorrecta el primer reparto de la contribución. Tras estas quejas, se formó una comisión formada por cuatro comisionados, dos de ellos fueron los hacendados don Rafael Morant y don Antonio Gosalbes y los otros eran dos comerciantes. Dicha comisión debía formar un papel de reflexiones y presentarlo en la Junta de Gobierno de forma que se tuviera en cuenta en el segundo reparto de dicha contribución. A pesar de estos acuerdos conciliadores, don Rafael Morant no se presentó a la Junta, que se celebró posteriormente, y a principios de mayo los hacendados comisionados no habían presentado papel alguno. Tampoco abonó ninguna cantidad, por lo que el gobernador Betegón escribió al capitán general del Reino de Valencia, don Domingo Izquierdo, enviándole una lista con los nombres de los deudores, ${ }^{73}$ quien poco después le autorizó para que exigiera las cantidades que debían. ${ }^{74}$ Los problemas económicos persistieron y se pensó en realizar un segundo reparto de los gastos de la epidemia, pero el propio consulado consideraba que no era conveniente pues quedaban aún deudores del primero y en caso de realizarse se obligaría a pagar a los mismos contribuyentes. El goberna-

70. AMA. Libro de Cabildos de 1805. Fols. 31v, 33. Sesión ordinaria del 15 de febrero de 1805. Dicho nombramiento llevaba fecha de San Ildefonso a 17 de septiembre de 1804. Según el interesado, dicho título le llegó el 8 de octubre de 1804. Sobre los regidores alicantinos, y sobre este caso particular, puede consultarse el trabajo de IRLES VICENTE, Ma del C. (1996), Al servicio de los Borbones. Los regidores valencianos en el siglo XVIII, València, Ed. Alfons el Magnànim/ IVEI, pp. 241, 242.

71. AMA. Libro de Cabildos de 1805. Fols. 31v, 33. Sesión ordinaria del 15 de febrero de 1805.

72. AMA. Sanidad. Legajo 1, n 5, h. 14. Carta de Pasqual Salazar y Antonio Serveix del Consulado al Sr. Josef Betegón, fechada en Alicante a 29 de abril de 1805.

73. AMA. Sanidad. Legajo 1, nº 5, h. 20. Carta del Sr. Betegón al Exmo. Sr. don Domingo Izquierdo, fechada en Alicante a 5 de mayo de 1805.

74. AMA. Sanidad. Legajo 1, n 5, h. 21. Carta de don Domingo Izquierdo al Sr. Betegón, fechada en el Real de Valencia a 14 de mayo de 1805 y AMA. Sanidad. Legajo 1, n 1, h. 9. Carta de Betegón a don Domingo lzquierdo, fechada en Alicante a 12 de marzo de 1805 . Ya con anterioridad Betegón el 5 de marzo de 1805 le había enviado una relación de sujetos que no había satistecho su parte en la contribución del medio millón. Le instaba en la urgencia del cobro y pedía instrucciones para conseguir el dinero que necesitaba. 
dor Betegón manifestó haber tomado a la fuerza varias cantidades para evitar que perecieran los enfermos y se «propagaran los males». Cantidades que por justicia debían reintegrarse a los interesados a la mayor brevedad, pues no debía perjudicarse a unos porque otros no hubieran satisfecho las cantidades a que estaban obligados. ${ }^{75}$ No sabiendo como obtener el dinero necesario para hacer frente a todos los gastos que ocasionaba la epidemia, Betegón escribió al capitán general del Reino, don Domingo Izquierdo:

"que ha disminuido el comercio en este puerto, espero se sirba V.E. decirme lo que deveré practicar en este caso, y particularmente el medio para tener caudales para los gastos urgentes, si por desgracia repite el contagio, que no lo espero, pues se asegura que estos comerciantes y hacendados han conducido sus intereses a sus casas de campo.»"

Como se trasluce del documento anterior, la generosidad de algunos de los comerciantes y de los hacendados en su aportación al bienestar de su propia ciudad y de la población dejó bastante que desear. Entre los nobles y hacendados que se retardaron en hacer efectiva su parte en los gastos cabe citar al marqués de Arneba y a don Francisco Valcárcel. Ambos protestaron de lo elevado de la contribución que les había correspondido, de carecer de efectivos, de haber repartido ya muchas limosnas y de tener que mantener a su cargo a un gran número de personas. ${ }^{77}$ Entre ellos y el gobernador se estableció un intercambio prolijo de cartas hasta que Betegón, colmada su paciencia, contestó a don Francisco Valcárcel:

"He visto con la debida atención el papel de V.S. de 5 del corriente, en que expresa que cree nadie le podrá exceder, en la puntualidad, al apronto de las contribuciones públicas y demás que miran al remedio de los miserables del común de esta ciudad. Así debe hacerlo todo buen Vasallo, y más en los casos como el de que se trata, que a nadie dejan libertad de contribuir según sus facultades al socorro de la afligida humanidad.

Los gastos han sido prontos y executibos, desde su principio, y mediado ya seis meses del reparto de la contribución del medio millón de reales con calidad de reintegro, veo con sentimiento mío, que no ha entregado V.S. ni un quarto. ${ }^{78}$

También contestó al marqués de Arneba en términos semejantes, ante sus quejas de inexactitud en las fumigaciones y la excesiva contribución atribuida:

«V.S. conoce mui bien que en estos asuntos, decide el dictamen de los físicos, y que de ellos no puedo ni debo separarme [...] Siéndome mui sensible que sin tener presente tan critica situación, en que no puede haver un orden premeditado, se critiquen mis operaciones por los ausentes y emigrados.» ${ }^{79}$

75. AMA. Sanidad. Legajo 1, nº 1, h. 4. Carta del Sr. Betegón al Sr. Fco. Valcárcel Pío de Saboya, fechada en Alicante a 7 de marzo de 1805.

76. AMA. Sanidad, Legajo 1, n 1, h. 9. Carta del Sr. Betegón al Sr. Izquierdo, fechada en Alicante à 12 de marzo de 1805.

77. AMA. Sanidad. Legajo 1, n 1, h. 2. Carta de don Fco. Valcárcel al Sr. Betegón, fechada en Musey a 10 de noviembre de 1804.

78. AMA. Sanidad. Legajo 1, n 1, h. 4. Carta del Sr. Betegón a don Fco. Valcárcel, fechada en Alicante a 7 de marzo de 1805. El subrayado es original del documento.

79. AMA. Sanidad. Legajo $1, \mathrm{n}^{\circ} 5$, h. 10. Carta del Sr. Betegón al marqués de Arneba, fechada en Alicante a 3 de abril de 1805 . 
Betegón premió el comportamiento de todos aquellos que permanecieron a su lado durante la epidemia, desempeñando las comisiones que se les ordenó, informando de su ejemplar comportamiento, "s" haciendo referencia especial a don Juan Falomir, como contralor del lazareto, así como a los diputados de barrio que también habían servido con mucho celo y actividad cuanto se les comisionó. En el mes de enero de 1805 se recibieron cartas de aquellos a quienes se había enviado la lista de los distinguidos por el servicio en la epidemia. El mismo Príncipe de la Paz aseguraba: «los protegeré por mi parte según merece su distinguida conducta». ${ }^{8 !}$ Por su parte don Pedro Ceballos informaba al gobernador de las palabras del rey: «que en su Real nombre les dé las gracias por el amor, que en esta ocasión han manifestado a la Patria y por el celo, y actividad con que han desempeñado las respectivas comisiones que han tenido.» ${ }^{\times 2}$

Junto con estas recomendaciones, el gobernador se encargó también de la sanción de los que defraudaron su confianza. Ya hemos visto que los regidores emigrados pretendían a su vuelta incorporarse a sus cargos. Por Real Orden se mandaba que «por entonces y hasta salir del peligro del contagio, continuaran sirviendo estos empleos los regidores interinos» nombrados por Betegón. En marzo de 1805, ante la proximidad del verano y el peligro de un nuevo brote de fiebre amarilla, el gobernador escribió al Príncipe de la Paz para que se les adjudicaran las regidurías a las personas que las desempeñaban interinamente desde que se declaró la epidemia, pues temía que al menor rumor de contagio todos los regidores paisanos emigrarían y volvería a quedarse sólo al frente de todas las disposiciones para el cuidado de la ciudad. ${ }^{\text {*3 }}$ De hecho hasta el 30 de octubre de 1805, pasado el verano, no se remitió desde San Lorenzo una real orden permitiendo que los regidores propietarios volvieran a ocupar sus empleos en el ayuntamiento alicantino. ${ }^{8+}$

80. AMA. Scinidad. Legajo 1, n 3, h. 1. Carta del Sr. Betegón al Sr. Lzquierdo, fechada en Alicante a 31 de dicienbre de 1804. Adjuntaba la relación de los militares y paisanos que durante la epidemia le habían servido con esmero: «haviendo sido los seis paisanos los únicos de este vecindario que han manifestado sa amor y celo por la patria, y a no ser por los militares, no se hubiera podido atender al buen orden $[. . .1$ Pueda ser que critiquen los que a nada se han prestado la conducta de algunos de los citados paisanos y puedo asegurar a V.E. que en mi [...] no les he notado irregularidades en sur conducta y que no tuve otros de quien valerme en los apuros en que the he visto durante el contagios. AMA. Sanidcd. Legajo 1, $\mathrm{n}^{\circ} 3$, h. 3. Documento fechado en Alicante a 31 de diciembre de 1804. «Recomendaciones...», en la h. 4, aparece la «Relación de los individuos, que desde el principio del contagio, que ha afligido a esta ciudad, hasta su conclusión, se prestaron al cuidado de los barrios, lazaretos, y demás disposiciones para la asistencia de los enfermos», fechado en Alicante a $1^{\circ}$ de enero de 1805 . Dicha relación se envió al Príncipe de la Paz-Godoy-, a don Miguel Cayetano Soler, a don Antonio Caballero y a don Pedro Ceballos.

81. AMA. Sunidad. Legajo 1, n 3, h. 5. Carta del Príncipe de la Paz al Sr. Betegón, fechada en Madrid a 9 de enero de 1805.

82. AMA. Sanidad. Legajo $1,11^{\circ} 3$, h. 7. Carta de don Pedro Ceballos al gobernador de Alicante, fechadat en Aranjuez a 19 de enero de 1805.

83. AMA. Sanidad. Legajo 1, $\mathrm{n}^{\circ}$ 12, h. 2. Carta del Sr. Betegón al Príncipe de la Paz, fechada en Alicante a 19 de marzo de 1805.

84. AMA. Libro de Cabildos de 1805. Fol. 172 v. Sesión ordinaria del 8 de noviembre de 1805. 
El comportamiento de los militares merece también atención. Junto a unos pocos ciudadanos alicantinos, fueron los únicos que permanecieron al lado del gobernador Betegón, si bien su condición militar les obligaba a la obediencia bajo fuertes sanciones en caso contrario. Los soldados contribuyeron a mantener el orden y las medidas de aislamiento, sufrieron los rigores de la situación, participando de la miseria de la población. En una ocasión el coronel Fulgosio escribió al gobernador Betegón informándole de que «los soldados del cordón inmediato a la costa carecen de pan y de todo sustento». Pedía dicho coronel que desde la villa de Elche se les proveyera de suministros, «pues de la plaza de Alicante no se les puede enviar cosa alguna», y concluía afirmando que «de desertarse algún soldado por dicho fallo no se le podrá imponer las penas prevenidas en la ordenanza». ${ }^{85}$ Otro oficio del 8 de octubre de 1804 denunciaba que las tropas destacadas en el barranco de las Ovejas, la casa de Verdú, el Huerto de las Palmeras y el Porquet -54 hombres del regimiento de América- no recibieron sus raciones de pan y demás vituallas desde el 4 de dicho mes y se solicitaban auxilios urgentes. ${ }^{86}$ Aunque toda la población sufrió penalidades es notorio el tratamiento preferente que recibían las viudas, padres pobres e hijos de los militares que fallecían con motivo de las epidemias, quienes tenían derecho a una pensión en virtud de resoluciones, de 1800 y 1804 , dictadas con motivo de las epidemias andaluzas. ${ }^{87}$ Para el resto de la población, la enfermedad o muerte del que ganaba el jornal en la familia suponía pasar hambre y miseria.

Los médicos de la propia ciudad, durante la epidemia, permanecieron en la misma prestando los auxilios que les fueron requeridos, sin embargo otros médicos se negaron y pusieron dificultades a acudir en auxilio de la población alicantina. En octubre de 1804, el gobernador de Orihuela escribió al gobernador de Alicante a propósito del envío a la ciudad infectada de dos médicos, pero todos se habían negado y sólo uno de los médicos titulares de Orihuela -entre halagos y amenazas- aceptaba la posibilidad de acudir, previa negociación de las condiciones económicas. ${ }^{88}$

Uno de los colectivos que no cumplió con las obligaciones de su cargo fue el de los escribanos públicos, a pesar de que, al día siguiente de la declaración de la epidemia, un bando del gobernador Betegón prohibía explícitamente «que ningún escribano ni empleado público pueda ausentarse de la ciudad sin licencia escrita». ${ }^{89}$ Varios testimonios revelan la negativa de los escribanos a realizar los testamentos de las personas enfermas de la fiebre amarilla por miedo al contagio. En estos casos los enfer-

85. Diario de Alicante, 14/XI/1927. No se indica la fecha, pero por la información que aporta parece que corresponde al mes de octubre de 1804.

86. Ibidem.

87. AMA. Correspondencia. Legajo 4, $\mathrm{n}^{\circ}$ 26. Carta al gobernador de Alicante, fechada en octubre de 1805. Se hace referencia a órdenes de S.M. sobre pensiones a las viudas, padres pobres e hijos de los fallecidos militares por el contagio de Andalucía por resoluciones de $1^{\circ}$ de noviembre de 1800 y 17 de noviembre de 1804.

88. AMA. Sanidad. Legajo 1, nº 8 bis. Carta de Juan de La Carte al Sr. Betegón, fechada en Orihuela á 16 de octubre de 1804.

89. Diario de Alicante, 12/X1/1927. Citado entre comillas como cita literal. Dicho bando no se encuentra ya entre los documentos del AMA. En la tesis de licenciatura de José María Palazón Azorín, (1977), op. cit., figura dicho bando del gobernador Betegón de fecha 14/IX/1804. 
mos lo realizaban ante diversos testigos que posteriormente eran citados cuando el testamento en cuestión se había de protocolizar para que resultase válido. ${ }^{*}$

Por último cabe señalar el comportamiento de los religiosos alicantinos, así como el fervor o el temor de Dios que este tipo de enfermedades generaba en la población. La aparición de la epidemia en la ciudad provocó entre sus habitantes el temor y el pánico. Una de las primeras órdenes reales fue la de celebrar rogativas públicas y prohibir los festejos. "' Las autoridades locales no consideraban conveniente la celebración pública de las mismas y ordenaron al cabildo eclesiástico que se realizaran de manera «secreta». Conforme el contagio fue intensificándose el fervor popular solicitó con mayor insistencia, e incluso violencia, el consuelo de la Santa Faz. Uno de los sacerdotes emigrados al comienzo de la epidemia escribió al gobernador justificando su huida por la insistencia de las gentes a traer a la ciudad la Santa Faz, a pesar de la prohibición al respecto. ${ }^{92}$ Dicha imagen permaneció en el Castillo durante la epidemia, pero debido a los gastos que ocasionaba al ayuntamiento, el cabildo del mismo decidió que se hiciera cargo de ella el cabildo eclesiástico «con el debido sigilo, a fin de evitar el concurso de gentes tan perjudicial en las actuales circunstancias, se traslade dicha Santa Reliquia a la Insigne Colegial de esta Ciudad». ${ }^{13}$ Las iglesias fueron cerradas durante la epidemia. Sólo en la iglesia de la Sangre de Cristo se permitió la administración de los sacramentos. Según el sacerdote don Vicente Spering habían muerto o enfermado muchos de los eclesiásticos y solicitaba al gobernador que designase una hora para sacramentar a los pacientes. Al margen de la solicitud aparecía una anotación, con toda probabilidad del propio gobernador, denegando tal petición pues según los médicos: «las actuales enfermedades son de una clase que de un instante a otro necesitan los enfermos que se les administre [los sacramentos]». ${ }^{94}$

Muchos de los sacerdotes permanecieron en la ciudad, pero otros muchos huyeron. Este fue el caso de Antonio Sala, quien en noviembre de 1804 justificaba ante el gobernador por escrito su huida, temiendo las represalias que pudiera acarrearle la misma, apelando a la amistad que al parecer existía entre ambos. Decía haber tenido que «ausentarse» con la mayor reserva pues, entre otras cosas, carecía de criados al habérsele muerto el capellán, la cocinera y otros dos criados más y sin poder trasladarse a su iglesia, que se hallaba infectada por los muchos muertos que se habían introducido de forma violenta. ${ }^{95}$ En una carta posterior este mismo sacerdote, aún emi-

90. Archivo Histórico Provincial de Alicante (AHPA). Protocolos Notariales. Sig. 690, ff. 27lv, 272, «no haver querido acudir, no obstante haverles llamado, escrivano alguno de la Universidad de San Juan para hazer o recibir el testamento.»; AHPA. Protocolos Notariales. Sig. 1.353. Expediente para protocolizar incluido tras el f. 20 del año 1805: «sin haver otorgado testamento ante escrivano público que le authorizase por no haverse encontrado para el efecto a causa del temor que tenian de contagiarse».

91. AMA. Libro de Cabildos de 1804. Fols. 160-161. Sesión del 19 de septiembre. También: AMA. Expedientes y Veredas. Arm. 15, Lib. 35. Año 1804. Fols. 657, 657v. Alicante, 19 de septiembre de 1804.

92. AMA. Sanidad. Legajo 1, nº 8 bis. Carta de D. Antonio Sala al gobernador Betegón, Orihuela, 15 de noviembre de 1804

93. AMA. Libro de Cabildos de 1804. Fol. 214. Sesión del 7 de diciembre de 1804.

94. Diario de Alicante, 19/XI/1927.

95. AMA. Sanidad. Legajo I, n 8 bis. Carta de don Antonio Sala al Sr. Betegón, fechada en Orihuela a 15 de noviembre de 1804 . 
grado, hacía referencia a «los muchos días que permaneci en Alicante confesando, administrando sacramentos, consolando y asistiendo a muchos epidemiados» ${ }^{96} \mathrm{Al}-$ gunos de los sacerdotes se negaron a administrar los sacramentos a los enfermos de fiebre amarilla por miedo al contagio. ${ }^{97}$ Otros sacerdotes sin embargo fueron objeto de reconocimiento por parte del cabildo municipal. Entre ellos don Juan Bautista Costa, don Leonardo Agustín Alberola y don Manuel Verdú. (98)

Enfermaron de fiebre amarilla, entre otros, el canónigo Salvador Santo Casanova. ${ }^{9 y}$ Hubo así mismo muchos sacerdotes que murieron víctimas de esta enfermedad, entre ellos don Vicente Beviá que falleció en el convento Hospital San Juan de Dios, don Tomás Sánchez -canónigo lectoral- y don Andrés Sala, que era el capellán de la ciudad. ${ }^{\text {(t) }}$

Mención aparte merece la dura tarea que realizaron los religiosos franciscanos que cuidaban del lazareto de curación, que como ya comentamos se estableció en el Convento de San Francisco, quienes permanecieron a su frente durante toda la epidemia. En octubre de 1804 elevaron sus súplicas al gobernador Betegón. Declaraban haber sufrido hasta entonces y tolerado «todas las indigencias». Habían dormido por más de doce días en el suelo «hecho, a la verdad, para hacer penitencia, pero no para descansar de las infatigables tareas de un lazareto en donde siempre han existido más de 300 enfermos» y se quejaban igualmente de tener que refugiarse en la «habitación librería, más bien una calle que lugar proporcionado para rezar y descansar», así como de la comida, «unos días sin nieve, otros sin ensalada». Durante un mes había tenido que mantenerse toda la comunidad con sólo raciones para dos personas. Al margen de la instancia dirigida por los franciscanos, el gobernador firmó un decreto ordenando:

"Los religiosos estén con todo alivio y buena asistencia, y si les acomoda recibir veinte reales de vellón por cada uno, diarios, para la manutención, facilitándoles un lego que los cuide.» ${ }^{101}$

En relación a las aportaciones económicas del clero, el 16 de octubre de 1804, el obispo escribió, desde Orihuela, condoliéndose por la situación de la población ali-

96. AMA. Sanidad. Legajo 1, nº 8 bis. Carta de D. Antonio Sala al Sr. Betegón, fechada en Orihuela a 23 de diciembre de 1804.

97. AHPA. Protocolos Notariales. Sig. 690. ff. 269v-272v. En los testamentos de D. Miguel Saludas -negociante- y Doña Eulalia Gras, viuda de D. Josef Saludas, madre del anterior, consta que estando enfermos en una hacienda de San Juan no quisieron acudir ni el reverendo cura de San Juan ni ninguno de los eclesiásticos de la iglesia parroquial a administrarles los sacramentos por lo que especificaban no tener los mismos «derecho alguno a mi funeral y obra pía» por no haber sido tratados como a sus feligreses.

98. AMA. Libro de Cabildos de 1804. Fols. 169, 169v. Sesión ordinaria del 9 de noviembre.

99. AMA. Sanidad. Legajo $1, \mathrm{n}^{\circ} 2$, h.4. Certificado médico realizado por Vicente Mas aportado para el retorno a Alicante del Canónigo Salvador Santo Casanova que enfermó de la fiebre amarilla. Fechado en Santa Faz a 4 de enero de 1805. Ibidem, h. 3. Carta del canónigo al Sr. Betegón solicitando entrar en Alicante, fechada en Santa Faz a 4 de enero de 1805.

100. AMA. Libro de Cabildos de 1804. Fols. 169, 169v. Sesión ordinaria del 9 de noviembre y fols. $162 \mathrm{v}$, 164. Sesión del 30 de octubre.

101. Diario de Alicante, 15/XI/1927. 
cantina y ofreció a Betegón que retirase de su cuenta en la casa de Die seis mil reales, por el momento, para ejercitar con ellos la caridad de distribuirlos entre los enfermos y necesitados, hasta que se habilitasen los curas y pudiera remitir otras cantidades. ${ }^{102}$ El propio obispo decía que había procurado auxiliarle a través de su vicario foráneo y curas de las iglesias de Alicante, pero no lo había conseguido por encontrarse la mayoría enfermos. Sin embargo, el día 18, don Vicente Spering escribió al gobernador en relación a la oferta del obispo informándole que éste ignoraba, por no habérselo podido comunicar el cura Rovira que había fallecido, que se habían tomado trescientos pesos de su orden para la caridad de los necesitados. Dicho dinero se había distribuido entre los curas de toda la ciudad y en la fecha todavía quedaban ochenta libras correspondientes a la Colegial, por lo que solicitaba a Betegón que suspendiera la orden de tomar la cantidad ofrecida por el obispo, pues ya se habían tomado cuatro mil quinientos reales. ${ }^{113}$ Al día siguiente el gobernador contestó a don Vicente Spering y haciendo caso omiso de las razones aducidas por éste alegaba:

"no está en mi arbitrio acceder a la solicitud de V.S., pues terminantemente dice sullltma. tome dicha cantidad para objeto tan piadoso y en ocasiones tan críticas en que se aumentan las miserias. ${ }^{\text {(n) }}$

Para finalizar este capítulo nos gustaría ofrecer un breve análisis de las últimas voluntades reflejadas en los testamentos en relación a las costumbres religiosas. ${ }^{105}$ Durante el tiempo que duró la epidemia no se observa un aumento del número de testamentos recogidos, con toda probabilidad por el hecho ya comentado de haberse negado los escribanos públicos a acudir junto a los enfermos para recoger sus últimas voluntades. Muchos de ellos hicieron testamentos en pliegos ante testigos para ser abiertos después de su muerte. ${ }^{160}$ En estos testamentos se repetían una serie de frases de contenido religioso. Estaban siempre presentes las llamadas «mandas forzosas» para los «lugares santos de Jerusalén y redempción de cautivos christianos» a los que se dejaba una cierta cantidad por una sola vez. Se especificaba la devoción a un determinado santo, pidiendo ser enterrado con un hábito determinado. En general el más solicitado por hombres y mujeres fue el hábito de San Francisco de Asís, del que algunos especificaban que fuera de la orden de Santa Clara y que por su devoción querían que fuese recogido del convento de la Santa Faz. Otros decían ser hermanos

102. AMA. Sanidad. Legajo $1, \mathrm{n}^{\circ} 8$ bis. Carta del Prelado Francisco Antonio, obispo de Orihuela al Sr. Betegón, fechada en Orihuela a 16 de octubre de 1804. AMA. Sanidad. Legajo 1, nº 8 bis. Carta de don Esteban Die al Sr. Betegón, fechada en Orgegia a 17 de octubre de 1804. Al día siguiente el gobernador recibió una carta de don Esteban Die quien, habiendo recibido la notificación del obispo, aceptaba dicho pago y solicitaba un recibo a su favor.

103. AMA. Sanidad. Legajo 1, $n^{\circ} 8$ bis. Carta de don Vicente Spering al Sr. Betegón, fechada en Alicante a 18 de octubre de 1804.

104. AMA. Sanidad. Legajo 1, nº 8 bis. Carta del Sr. Betegón al Sr. Spering, fechada en Alicante a 19 de octubre de 1804.

105. AHPA. Protocolos Notariales. Sig. 90, 91, 219, 288, 289, 581, 690, 938, 1353 y 1686. Corresponden a diversos escribanos y son relativos a los años 1803,1804 y 1805 . La mayoría corresponden a la localidad de Alicante y alguno a la Universidad de San Juan y Benimagrell.

106. AHPA. Protocolos Notariales. Sig. 90, f. 201 y Sig. 1353, año 1805. 
de la tercera orden de la Santa Hermandad de San Francisco de Asís. Entre las mujeres también era frecuente la petición de ser enterradas con el hábito de nuestra señora del Carmen del convento del patriarca San Josef orden de Ntra. Sra. del Carmen de Alicante, mientras que alguna mujer pidió ser enterrada con las «basquiñas más viejas» que tuviera, y otros delegaban estas disposiciones a los albaceas que nombraban en su testamento. La mayoría solicitaba misas cantadas estando su cuerpo presente y para el socorro de su alma disponía una cierta cantidad de misas rezadas, repartidas en una serie de iglesias o conventos, mediante el pago de una limosna por cada una de ellas. En general, un tercio de estas misas se otorgaba a la propia parroquia y las otras solían repartirse entre los conventos de las comunidades de mendicantes de la ciudad de Alicante: Santo Domingo, San Francisco, el Carmen y San Agustín. ${ }^{1117}$ El poder económico del que testaba se refleja en la limosna destinada a su obra pía, que en ocasiones era muy elevada. En otras ocasiones el testamento era un documento destinado a regular sus posesiones en previsión de la muerte. En este sentido, durante la epidemia de fiebre amarilla dos irlandeses, comerciantes, que se encontraban con motivo de la misma en la Partida de la Condomina realizaron su testamento «sano de toda enfermedad» pero «queriendo dejar las cosas así regladas para el descanso de mi almucts. "1is

Otro de los deseos expresados en el testamento era el de ser enterrado en ataúd en el cementerio de las almas existente en la parroquia -en el caso de San Juan- o en la iglesia de San Nicolás, Santa María o algunos de los conventos de la ciudad. Muchas personas tenían sepulcros propiedad de la familia o «vasos» en las propias iglesias. Se observa que en el año de la epidemia y posterior, debido a la reiterada prohibición de realizar enterramientos en el interior de los templos, algunos especifican «si el govierno lo permitiese, y quando no, lo serán con arreglo a las órdenes que haya expedidas para ello»o bien «enterrado si se permitiese en la iglesia...». ${ }^{10 \%}$

A modo de conclusión señalaremos que las diversas reacciones observadas en la población alicantina, como respuesta a la aparición de la epidemia de fiebre amarilla en 1804, coinciden en su mayoría con las descritas en la historiogratía con motivo del análisis de otras epidemias. Las clases sociales más deprimidas sufrían con anterioridad a la declaración de la epidemia los rigores de la grave crisis agrícola y económica que imperaba y que se tradujo en hambre generalizada y falta de empleo. Situación que se agravó durante la misma. Las medidas dictadas no fueron respaldadas con demasiado entusiasmo por el grueso de la población, por cuya causa tuvieron que imponerse a la fuerza mediante sanciones que oscilaban desde multas a la pena de muerte. Como se ha señalado en otros estudios similares, ${ }^{10}$ las desigualdades sociales se pu-

107. Sobre los mendicantes y el clero es interesante la obra de WEBSTER, J.R., (1998), Els mendicants $i$ el clergat al Pás Valencià. Valencia. Afers. Atiende a Ia competencia entre las parroquias y las órdenes mendicantes por el bienestar espiritual de los fieles, lo que comportaba un enfrentamiento relacionado con las aportaciones de limosnas y donativos que recibían de ellos, derechos en los enterramientos, etc. Especialmente pp. I27-134 y $139-141$.

108. AHPA. Protocolos Notariales. Sig. 1686. ff. 24v-27.

109. AHPA. Protocolos Notariales. Sig. 1353, f.5 y Sig. 938, 1. 69.

110. Ver las obras que se citan en la nota 1. 
sieron de manifiesto en las opciones que los diversos sectores de la sociedad alicantina dispusieron ante la enfermedad. Mientras las personas adineradas pudieron emigrar de la ciudad y refugiarse en el campo u otras poblaciones, los que carecían de recursos hubieron de permanecer en la misma. Mientras unos, tras enfermar, podían recobrarse en casas de campo, los otros debían ir obligatoriamente al lazareto de curación donde reinaban unas condiciones infrahumanas que provocaban el rechazo de la población. Además de desarraigar a los enfermos del ambiente familiar, tampoco garantizaban la curación sino su aislamiento, para proteger a los individuos sanos. Las medidas de aislamiento produjeron una elevación de los precios de los alimentos que dificultó el abastecimiento de la población y provocó graves conflictos en los puntos del cordón sanitario donde se celebraban los mercados. Las condiciones de hambre y miseria tuvieron su punto culminante en enero de 1805, hasta el extremo que se temieron revueltas violentas por parte de los vecinos para obligar a las autoridades a abrir la comunicación de la ciudad con el exterior, el puerto y la fábrica de cigarros. 